\title{
Is Immigrant Neighborhood Inequality Less Pronounced in Suburban Areas?
}

\author{
Chad R. Farrell* \\ Department of Sociology \\ University of Alaska Anchorage \\ Glenn Firebaugh \\ Department of Sociology \\ Pennsylvania State University
}

January 22, 2016

* Please direct correspondence to Chad R. Farrell, Department of Sociology, University of Alaska Anchorage, 3211 Providence Drive (SSB 372), Anchorage, AK 99508-4614 (crfarrell@uaa.alaska.edu). 


\title{
Is Immigrant Neighborhood Inequality Less Pronounced in Suburban Areas?
}

\begin{abstract}
We investigate suburbanization and neighborhood inequality among 14 immigrant groups using census tract data from the 2008-2012 American Community Survey. Immigrant neighborhood inequality is defined here as the degree to which immigrants reside in neighborhoods that are poorer than the neighborhoods in which native whites reside. Using city and suburb Gini coefficients which reflect the distributions of groups across neighborhoods with varying poverty rates, we find that the immigrant-white gap is attenuated in the suburbs. This finding applies to most of the nativity groups and remains after accounting for metropolitan context, the segregation of poverty, and group-specific segregation levels, poverty rates, and acculturation characteristics. Despite reduced neighborhood inequality in the suburbs, large group differences persist. A few immigrant groups achieve residential parity or better vis-à-vis suburban whites while others experience high levels of neighborhood inequality and receive marginal residential returns on suburban location.
\end{abstract}

Keywords: neighborhood, inequality, suburb, immigrant, poverty, segregation 


\section{Introduction}

Despite idyllic images of spacious homes, good schools, and safe streets, it is clear that portions of suburbia are struggling (Allard and Roth 2010). Suburbs have never been quite as homogenous as popular images would have us believe (Jackson 1987), and some suburban neighborhoods experienced a precipitous decline during the economic volatility of the 2000s. According to recent analyses by Kneebone and Berube (2013), the first decade of this century saw the suburban poverty population in the nation's largest metropolitan areas increase by 53 percent while the poverty population in cities increased by less than half that rate. As a result, 2010 became the first decennial year in which the suburban poor outnumbered the urban poor.

At the same time, a "suburban immigrant nation" (Hardwick 2008) has emerged in the wake of deindustrialization, dispersed employment, and new immigration from Latin America and Asia (Liu and Painter 2011; Singer 2005; Singer et al. 2008). The suburbs are now the first destination of many incoming immigrants rather than a residential stepping stone from the city. This trend runs counter to previous periods in which just a few gateway cities housed the bulk of the foreign-born population. As a result, three out of every five immigrants in large metropolitan areas reside in the metropolitan periphery (Wilson and Singer 2010). This has contributed to the widespread diversification of communities within metropolitan areas (Lee et al. 2014) and to the emergence of "melting pot suburbs" which have blurred historical color lines (Frey 2011).

In light of the growing suburbanization of immigrants, it is an opportune moment to reconsider the residential circumstances of immigrants in relation to the highly suburbanized U.S.-born white population. From prior research we know that immigrants tend to live in poorer neighborhoods than natives (Galster et al. 1999; Hall and Greenman 2013; Rosenbaum and Friedman 2007; White and Sassler 2000) but we do not know whether the disparities are greater 
for immigrants who live in cities or in suburbs. Most of the research on recent immigrant settlement patterns to this point has focused on residential segregation (Cutler et al. 2008; Farrell 2016; Hall 2013; Iceland 2009). However, to quote Alba et al. (2014, p. 2), "segregation research offers a limited window on residential situations: knowing how segregated a group is does not necessarily tell us what kinds of neighborhoods its members typically live in.” In fact, segregation is only one of several factors determining the degree of residential inequality for groups (Quillian 2012). ${ }^{1}$

Rather than using segregation as a proxy for neighborhood inequality, then, we tackle the issue directly by focusing on the degree to which immigrant groups reside in disparate economic environments when compared to U.S.-born whites. Specifically, we are interested in assessing whether suburbanization attenuates the immigrant-white gap in neighborhood socioeconomic conditions. While there have been efforts to measure neighborhood inequality among broadly defined ethnoracial groups (Osypuk et al. 2009; Timberlake 2002; Timberlake and Iceland 2007), we extend that analysis by examining neighborhood inequality broken down by suburb and city for 14 immigrant groups in the metropolitan United States. Drawing on a tailored version of the Gini index (Firebaugh and Farrell 2011) we measure immigrant neighborhood inequality using tract poverty rates from the 2008-2012 American Community Survey. Our research is guided by three questions: 1. Do immigrants experience different levels of neighborhood inequality vis-à-vis native whites in cities and suburbs? 2. Do city/suburb differences remain after taking into account metropolitan context, segregation, and socioeconomic and acculturation characteristics of immigrant groups? 3. Do immigrant neighborhood inequality patterns differ by country of origin?

\footnotetext{
${ }^{1}$ Hypothetically at least, native and foreign-born populations could live in segregated neighborhoods while still experiencing equivalent levels of localized poverty.
} 
The answers to these questions are not straightforward. On one hand, housing discrimination, low-density zoning, white flight, and nativist animus on the part of incumbents could produce greater suburban neighborhood inequality by pushing suburbanizing immigrants into distressed areas (Fennelly and Orfield 2008; Odem 2008). Alternatively, immigrants arriving in the United States with high levels of education and income may seek out suburban enclaves that are both affluent and ethnically distinct (Li 1998, 2006; Logan et al. 2002), resulting in narrower disparities in suburban areas for certain groups. Of course, both forces could be at work, and the relative importance of the forces likely varies across the immigrant groups. Our objective in this paper is to determine whether, for each of the groups, the disparity in neighborhood poverty for immigrants and native whites tends to be greater in suburban areas or in central cities.

\section{Immigrant Suburbanization and Neighborhood Inequality}

Although there is a growing literature addressing recent residential segregation patterns in the context of immigration (Farrell 2016; Hall 2013; Iceland 2009; Lee et al. 2014; Lichter et al. 2010), there are significant gaps in our knowledge about immigrant neighborhood inequality - the degree to which immigrant groups reside in poorer neighborhoods than U.S.born whites do-particularly with respect to suburban areas. The issue is important because residence in disadvantaged neighborhoods is associated with a variety of social ills including high school dropout (Crowder and South 2011), violent juvenile crime (Ludwig et al. 2001), depression (Kim 2010), lower cognitive ability (Sharkey and Elwert 2011), and diminished life satisfaction (Firebaugh and Schroeder 2009). Moreover, long-term exposure to localized disadvantage can have adverse effects across generations (Sharkey 2008). Disparities in neighborhood poverty may only be partly due to aggregate differences in household income 
across racial and nativity groups. In New York City, for example, black and Latino immigrant families live in lower quality neighborhoods than white families even after controlling for a range of relevant household characteristics (Rosenbaum and Friedman 2007).

Concentrated affluence also matters (Massey 1996; Bischoff and Reardon 2014). White populations are growing rapidly in outlying exurbs as suburbanization exacerbates the spatial segregation of prosperity (Dwyer 2010; Frey 2011). This has implications for racial neighborhood inequality, since affluent suburban blacks and Hispanics reside in neighborhoods with poverty rates much higher than those experienced by affluent suburban whites (Logan 2014). However, Lee and Marlay (2007) identify substantial concentrations of immigrants in affluent neighborhoods, most of which are found in the suburbs. Combined with their additional finding that Asians are overrepresented in wealthy neighborhoods, it is possible that certain suburbanized immigrant groups could be residentially advantaged relative to suburban whites. This underscores the need to focus on specific country-of-origin groups rather than relying on broad panethnic classifications.

Suburbanization has traditionally been viewed as the spatial manifestation of acculturation and upward mobility for immigrants and their offspring (Alba and Logan 1991; Massey 1985). This process of spatial assimilation is predicted not only to increase residential integration with majority group households but also to improve the residential circumstances of the immigrant groups themselves (Rosenbaum and Friedman 2007). Existing research on spatial assimilation generally focuses on the former, assessing whether socioeconomic advancement (e.g., income, education) or acculturation (e.g., English language proficiency) among minority groups leads to greater residential proximity to whites. By contrast, we treat residential segregation as a predictor rather than a proxy for immigrant neighborhood inequality. 
Specifically, we are interested in whether suburban immigrants are more likely to achieve residential parity in neighborhood economic characteristics with whites irrespective of their residential proximity to them. Thus we investigate whether, and to what degree, segregation in cities and suburbs accounts for neighborhood disparities among immigrants and U.S.-born whites. In addition, we seek to test whether, consistent with the spatial assimilation perspective, economic and acculturation characteristics explains any suburban effect on neighborhood inequality.

A segmented version of the assimilation model (Portes and Zhou 1993) posits differing residential trajectories conditioned by national origin, enclave size, and reception by the host society. A simple straight-line version of the spatial assimilation model suggests that accounting for the aforementioned socioeconomic and acculturation characteristics should explain away any group differences in residential patterns. By contrast, the segmented model recognizes the different economic, regional, and historical circumstances under which various immigrant groups enter the United States and predicts group differences to persist even after controlling for socioeconomic status and acculturation. This is one of the reasons we look at specific country-oforigin groups rather than the aggregate foreign-born population.

The place stratification perspective provides a more pessimistic view about the spatial assimilation, emphasizing the obstacles to residential attainment for racial and ethnic minorities, including new immigrants in the suburbs. These barriers include continued racial discrimination in housing and lending (Pager and Shepherd 2008), anti-density zoning (Rothwell and Massey 2009), and resistance on the part of native incumbents (Fennelly and Orfield 2008). Given that many of these realities are playing out anew in the suburbs, a place stratification approach might predict greater residential inequality for newcomers in the suburbs than would be found in 
established cities. It would also point to residential segregation from whites as one of the major factors figuring into neighborhood inequality.

A number of past studies have investigated the neighborhood circumstances of immigrant groups (Adelman et al. 2001; Cort 2011; Galster et al. 1999; Hall and Greenman 2013; White and Sassler 2000). But these studies seldom assess the degree to which residential disparities differ by city versus suburb. Prior studies of residential attainment that do take the suburbs into account generally find that, consistent with spatial assimilation, suburban location is associated with residential advantages for immigrants. For example, Alba et al. (2000) find that in five large metropolitan areas Asian and Hispanic immigrant suburbanites reside in more affluent neighborhoods (as measured by median household income) than do their city counterparts. Most pertinent to our study, they find that the white-immigrant gap in neighborhood income also narrows in the suburbs. So, compared to city-dwellers, immigrant suburbanites were not only better off in absolute terms but also were on a more equal residential footing relative to whites.

In another study, Friedman and Rosenbaum (2007) use several subjective indicators from the American Housing Survey to assess neighborhood quality among residents. They find that foreign-born blacks, Hispanics, and Asians in the suburbs report less exposure to localized disorder than their coethnics in the cities. When comparing the perceived neighborhood conditions of immigrant suburbanites to native whites, however, some interesting patterns emerge. Net of household income and other variables, whites actually experience more neighborhood disadvantage than certain immigrant groups on the neighborhood quality indicators. For example, Asian immigrants in the suburbs are less likely than white suburbanites to report trash near their homes (see also White and Sassler 2000). By contrast, foreign-born blacks are disadvantaged in relation to whites whether they live in suburbs or central cities, and 
there is some evidence that their residential fortunes are worse in the suburbs. Hispanic immigrants are also residentially disadvantaged (compared to whites) in both the cities and the suburbs with regard to litter, lack of open spaces, and the presence of nearby buildings with bars on windows. This is consistent with other research finding Hispanic immigration to be associated with higher rates of neighborhood poverty proximity in the suburbs (Holliday and Dwyer 2009).

Rather than relying on broad panethnic classifications, a few other studies have looked at more refined samples of country-of-origin groups. Alba et al. (1999) find that the link between acculturation and suburbanization weakened for several groups, as English bilingual Cubans, Chinese, Filipinos, and Koreans were no less likely to reside in suburbs than English monolingual coethnics. Similarly, Argeros (2013) finds that recent Caribbean immigrants with low English-language proficiency are more likely to be living in the suburbs than their more acculturated coethnics, but these Caribbean suburbanites reside in disadvantaged areas relative to native whites. These results suggest that suburban areas are becoming more open to less acculturated immigrants, but that the suburban areas in which the immigrants are settling are disadvantaged relative to the residential environments of typical white suburbanites. Immigrant clustering in "ethnoburbs" (Li 1998) nonetheless does not always indicate residential disadvantage. Logan et al. (2002) compare the city versus suburb neighborhood contexts of several immigrant groups for New York and Los Angeles. They find that a variety of groupsincluding Mexicans, Chinese, Vietnamese, and Cubans - are more likely to reside in ethnically distinct neighborhoods in the suburbs than they are in cities and that in many cases these suburban ethnic neighborhoods are characterized by higher incomes and lower poverty rates than city neighborhoods. Apparently, then, some groups do not need to be residentially intermingled with native whites to experience suburban neighborhood amenities. 
Although these studies enrich our understanding of the residential circumstances of immigrant groups in America, they suffer from a number of limitations. First, they often rely on broad panethnic categories that do not allow for an assessment of specific country-of-origin groups. Second, research that does incorporate detailed groups often relies on small samples of a few large metropolitan areas, thereby excluding many of the new destinations to which immigrants are dispersing (e.g., see Hall 2013; Lichter and Johnson 2009). Third, some studies have treated suburban location or proportion white as indicators of neighborhood socioeconomic context (Alba et al. 1999; Argeros 2013; Galster et al. 1999), leaving unmeasured the actual socioeconomic conditions of suburban areas. Our research overcomes many of these limitations by assessing immigrant neighborhood inequality in city and suburban neighborhoods across all U.S. metropolitan areas with a significant immigrant presence. It includes a large and diverse sample of immigrants from 14 different countries of origin located in Asia, the Caribbean, and Latin America. Finally, it uses a measure of neighborhood inequality that takes into account the entire distribution of neighborhood economic environments - as measured by poverty ratesinhabited by immigrant and native residents.

\section{Data and Methods}

\subsection{Data}

This study uses census tract data from the 2008-2012 American Community Survey (ACS) 5-year estimates to document the settlement patterns of immigrants from five Asian countries (China, India, Korea, Philippines, Vietnam), five Latin American countries (Colombia, El Salvador, Guatemala, Honduras, Mexico), and four Caribbean countries (Cuba, Dominican Republic, Haiti, Jamaica). All 14 groups had population sizes above 500,000 according to the 2012 ACS estimates. Neighborhood economic characteristics are captured using ACS estimates 
of tract poverty rates. We compare the residential circumstances of the 14 groups to the U.S.born segment of the non-Hispanic white population. We choose white metropolitan residents as the reference group for four reasons. First, they are the most suburbanized ethnoracial group in the United States (Frey 2011). Second, over half of the white poor are suburbanized, a larger suburban share than that found for black, Asian, or Hispanic poverty populations (Howell and Timberlake 2014). Third, white residents are the group most likely to express misgivings about racial residential integration (Charles 2003). Fourth, their mobility patterns are particularly sensitive to the size and growth of local immigrant populations (Crowder et al. 2011). Although we focus on inequality between immigrant groups and U.S.-born whites, our measures of neighborhood poverty rates reflect the neighborhood's entire population. This is critical because the presence of poor (or nonpoor) non-group neighbors (e.g., other immigrants, native nonwhites) also figures into the localized conditions to which our focal groups are exposed (Quillian 2012).

We begin by comparing immigrants to US-born whites in all 366 metropolitan areas in the United States $\left(57,752\right.$ neighborhoods [census tracts] in all). ${ }^{2}$ Subsequent analyses include only those metros that have at least 1,000 immigrant group members in both the city and suburb. There are 160 of these metropolitan areas, 84 of which have a single immigrant group meeting both the city and suburb population thresholds. The remaining 76 have multiple groups with sufficient city and suburban populations; two of these (New York and Chicago) have all 14 immigrant groups represented. We rely on 2009 Office of Management and Budget (OMB) definitions of metropolitan areas, which are considered "an economically and socially linked collection of large and small communities" (Frey et al. 2004; p. 2). There is a lively scholarly

\footnotetext{
${ }^{2}$ All census tract data were extracted from demographic tables provided on the Social Explorer website (www.socialexplorer.com). Tracts with over one-quarter of the population in group quarters in either of the two previous decennial enumerations are excluded.
} 
debate revolving around the definition, demarcation, and classification of "suburbs" (Harris and Lewis 2001; Kruse and Sugrue 2006; Sharpe and Wallock 1994). In fact, the OMB does not use the term. It does, however, identify principal cities that meet specific population and employment criteria. We follow this lead and opt for a simple population size criterion, operationalizing suburban territory as metropolitan tracts located outside principal cities of 50,000 or more. In cases where a tract crosses the boundaries of a principal city, we assign city or suburban status based upon where the majority of the tract population is located. In metropolitan areas with multiple principal cities meeting our population threshold, tracts are aggregated to create a single city estimate of neighborhood inequality. ${ }^{3}$

\subsection{Measuring Neighborhood Inequality}

In our framework, neighborhood inequality exists between two groups when the members of one group tend to reside in higher income (here, lower-poverty) neighborhoods than members of the other group (Firebaugh and Farrell 2011). We measure this inequality with a version of the Gini coefficient that has been used previously to measure racial residential segregation (Duncan and Duncan 1955; Massey and Denton 1988). The Gini is particularly well-suited to this task because it meets all the criteria for a valid measure of inequality (Allison 1978; James and Taeuber 1985; Reardon and Firebaugh 2002). To calculate the Gini coefficient for immigrant neighborhood inequality, we first order the census tracts $(j=1,2, \ldots, \mathrm{J}$ units $)$ based on their neighborhood poverty rates. We keep a running tally of the cumulative proportions of immigrants $\left(\mathrm{X}_{j}\right)$ and U.S.-born whites $\left(\mathrm{Y}_{j}\right)$ while moving from the most to the least

\footnotetext{
${ }^{3}$ We experimented with a larger city population threshold of 100,000. This did little to affect mean levels of immigrant neighborhood inequality across groups and locations, though it did result in dropping several metropolitan areas that lacked principal cities of at least 100,000. Most of these small metros (N=42) include sizable immigrant populations of Mexican origin, so a larger city population criterion excludes a disproportionate number of smaller Mexican immigrant destinations. Overall, excluding these areas does not have much impact on our estimates of Mexican neighborhood inequality in cities and suburbs. However, we prefer to retain these metros (and the 50,000 city criterion) in order to expand our coverage to as many areas as possible.
} 
disadvantaged tracts (highest to lowest poverty rate). The Gini then takes the form (Duncan and Duncan 1955):

$$
\mathrm{G}=\sum_{j=1}^{J} X_{j} Y_{j-1}-\sum_{j=1}^{J} X_{j-1} Y_{j}
$$

Complete equality $(\mathrm{Gini}=0)$ indicates that equal proportions of immigrants and native whites reside in poor and nonpoor neighborhoods; there is no difference in the poverty rates of neighborhoods where immigrants and whites live. Complete inequality $(\mathrm{Gini}=1)$ occurs when all immigrants are found in more disadvantaged neighborhoods than all U.S.-born whites.

We calculate Gini coefficients for cities and suburban areas for each of the immigrant groups. This can be depicted with a Lorenz curve (Lorenz 1905; Gastwirth 1972), with the Gini coefficient representing the proportion of the area below the diagonal that falls within the curve. Figure 1 illustrates this by showing city and suburb Lorenz curves for poverty-based neighborhood inequality between the foreign-born and U.S.-born white population for all metropolitan tracts in the United States. It plots the cumulative proportions of the immigrant population (x-axis) by the cumulative proportions of U.S.-born whites (y-axis) after sorting all city tracts $(\mathrm{N}=22,981)$ and all suburban tracts $(\mathrm{N}=34,771)$ by their respective poverty rates. When moving along the $\mathrm{x}$-axis, then, the highest poverty tracts are found on the left and the poverty rates decrease as one moves to the right. The diagonal represents neighborhood equality $($ Gini $=0)$ between the two groups.

[Figure 1 about here]

The shallower suburban curve (and smaller Gini) in Figure 1 indicates that immigrants and native whites reside in more comparable (though still unequal) poverty environments in suburban areas than in cities. This is not to say that immigrant and native whites are more likely 
to live in the same neighborhoods when they live in the suburbs, as these curves depict residential inequality, not residential segregation. ${ }^{4}$ Note that the point $(50,30)$ lies on the Lorenz curve (or nearly so) for cities. This indicates that, in cities, about $100-30=70$ percent of whites live in a tract with less poverty than the tract in which the typical (median) immigrant lives; in the suburbs that figure is closer to 65 percent (Figure 1). While this does not appear to be a large difference, it is worth considering that roughly 5.3 million white suburbanites $(\sim 5 \%$ of white suburbia) would have to move to a poorer neighborhood in order to make these suburban and city curves identical at the median. From the Lorenz curves we see that - in both central cities and suburbs - immigrants typically reside in poorer neighborhoods than whites. At most neighborhood poverty levels the disparity is greater in cities. At the left side of the figure, however, the suburban curve lies below the curve for cities, indicating that the poorest neighborhoods in the suburbs house disproportionately more immigrants than the poorest neighborhoods in cities.

Of course, there are many reasons to suspect that different country-of-origin groups will exhibit very different curves. Figure 2 displays Lorenz curves for four groups that embody distinct patterns of city/suburb neighborhood poverty inequality. Like Figure 1, these curves represent all the city and suburban tracts in America irrespective of metropolitan context. With a Gini score of just .073, Chinese city-dwellers do not experience much neighborhood inequality in relation to native whites. In suburban tracts, there is actually a greater Chinese-white neighborhood disparity, but the Lorenz curve is above the diagonal, indicating "reverse inequality" (a negative Gini) - Chinese suburbanites are the advantaged group, experiencing lower poverty environments than the white suburban population. By contrast, Dominican

\footnotetext{
${ }^{4}$ The undifferentiated immigrant/white segregation Ginis are virtually identical $(\mathrm{G}=.70)$ for both city and suburban tracts.
} 
immigrants reside in far more disadvantaged residential circumstances than do Chinese immigrants. The Dominican city/suburb comparison nonetheless is consistent with the idea that suburbs are less unequal, as Dominican suburban residents register a Gini score that is only twothirds the size of the Gini for Dominican city residents. A different story is seen in the bottom half of Figure 2. While Haitian-white neighborhood inequality is lower than it is between Mexicans and whites, in both cases immigrant suburbanites are found in relatively more disadvantaged residential circumstances vis-à-vis whites than are their coethnics in cities. The city/suburb differences are not large, but these two sets of Lorenz curves indicate that suburban residence does not necessarily reduce immigrant-white disparities for all groups. Analyses below will further disaggregate these curves so as to generate city and suburb Ginis for each metropolitan area.

[Figure 2 about here]

\subsection{Multivariate Models}

Our analytic objective is to determine whether the immigrant-white disparity in neighborhood economic conditions is attenuated in suburban areas and, if so, whether that attenuation is greater for some immigrant groups than for others. Unlike studies of locational attainment (Alba and Logan 1991; Crowder and South 2005; Logan et al. 1996; Rosenbaum and Friedman 2007; Sampson and Sharkey 2008; South et al. 2005; Woldoff and Ovadia 2009), we are less interested in the mechanisms that sort households into neighborhoods than we are in the end product of those mechanisms. Thus we focus on the distribution of immigrant households across neighborhoods and metropolitan areas, not on individual households themselves, to address the question of how immigrant groups are faring with respect to residential conditions. 
Our modeling framework draws from one developed in the segregation literature (Hall 2013; Iceland and Scopilliti 2008; Massey and Denton 1989). Our dependent variable is povertybased neighborhood inequality, as measured by the Gini index. For each of the 14 immigrant groups, we calculate immigrant-white Ginis separately for the central city and its suburbs, so each metropolitan area provides a city and suburb Gini for every group that meets the population size criteria. For example, the Atlanta metropolitan area contributes two Mexican-white neighborhood poverty Ginis, two Guatemalan-white poverty Ginis, and so on. Our combined sample includes 1,076 group- and place-specific neighborhood inequality Ginis. We then regress neighborhood inequality on a host of group and metropolitan predictors. Our models feature robust standard errors adjusted for the clustering of observations within metropolitan areas.

The full model includes dummy variables for suburban location and country of origin along with variables reflecting the overall rate of poverty, group-specific population size, and Gini coefficients measuring the segregation of all poor and all nonpoor residents and the segregation of each immigrant group from the U.S.-born white population. We also seek to control for other group characteristics relevant to immigrant settlement patterns in cities and suburbs. The spatial assimilation perspective predicts that both economic and acculturation characteristics are important predictors of immigrants' residential contexts. Unfortunately, the 2008-2012 ACS summary files do not provide economic and acculturation characteristics for specific groups by nativity. However, the ACS does provide these characteristics for metropolitan areas and principal cities in its 2006-2010 5-year estimates. We use these earlier summary files to create city and suburban estimates of group-specific poverty ratios (with nonHispanic white poverty rates serving as the denominator), recent immigrant arrivals (\% entering the U.S. since 2000), and proficiency with the English language (\% speaking English only, "very 
well", or "well"). ${ }^{5}$ Note that, while our measure of neighborhood inequality is based on data at the neighborhood (tract) level, our data on group-specific economic conditions and acculturation are at the city and suburb level. So, for example, when we note below that areas with concentrations of recent Chinese arrivals exhibit higher levels of neighborhood inequality, we cannot say conclusively that recent Chinese immigrants are more likely to live in disadvantaged neighborhoods than more established Chinese immigrants because we do not know how recent and more established Chinese immigrants are distributed across neighborhoods. However, we do know the distribution of native whites and foreign-born Chinese across neighborhoods, so we can determine whether Chinese immigrants are more likely to live in higher poverty neighborhoods than native whites.

Finally, our models include a battery of metropolitan controls drawn from the segregation literature (Logan et al. 2004; Lee et al. 2008). We include population size, overall metro suburbanization, and region, as well as the metro population's percent black, percent foreignborn, and percent of retirement age. Metropolitan housing characteristics are reflected in the vacancy rate and the rate of new construction (percentage of housing units built in the most recent decade). Functional specialization as a military, university, or manufacturing center is measured with the percentage of the labor force in the Armed Forces, percentage of the population aged 15 years and over enrolled in college, and the percentage of the employed labor force engaged in manufacturing.

\footnotetext{
${ }^{5}$ Our full models are reduced from 1,076 to 1,034 cases due to missing data.
} 


\section{Results}

\subsection{Patterns of Immigrant Suburbanization}

Table 1 provides information on the patterns of suburbanization among the 14 immigrant groups included in the analysis. Each of the immigrant groups is less suburbanized than the U.S.born white (hereafter "white") population, but there are large differences across groups. Among groups hailing from Asia, Indians exhibit the highest levels of suburbanization (60 percent) and Chinese the lowest (43.7 percent). Among Caribbean immigrants, Cubans have rates of suburbanization (71.6 percent) nearly as high as whites (72.6 percent) while Dominicans (39.3 percent) have the lowest levels of suburbanization of all the groups. The Latin American groups also have uneven settlement patterns. Guatemalans, Hondurans, and Mexicans have suburbanization rates below 50 percent while nearly two-thirds of Colombians (65.9 percent) are suburbanized. Despite their low levels of suburbanization, Mexican immigrants make up more than a quarter of foreign-born suburbanites. All told, the 14 immigrant groups included in Table 1 constitute about 64 percent of all foreign-born suburbanites. ${ }^{6}$

[Table 1 about here]

\subsection{Immigrant Neighborhood Inequality Within Metropolitan Areas}

Results based on all census tracts mixed together (as in Figures 1-2) tell us the extent of the relative neighborhood disadvantage (or advantage) of immigrant groups compared to whites for the U.S. metropolitan population as a whole. But immigrant groups are not distributed proportionately across metropolitan areas and given the substantial differences in poverty across U.S. metropolitan areas, the level of neighborhood disadvantage (or advantage) that immigrants experience in the metropolitan areas where they are concentrated could differ from the

\footnotetext{
${ }^{6}$ Canadian and European immigrants tend to be highly suburbanized (Farrell 2016), accounting for much of the residual foreign-born suburban population not included in our sample.
} 
inequalities based on metropolitan areas collectively. To adjust for the disproportionate distribution of immigrant groups across metropolitan areas that vary in poverty, we first estimate separate city and suburb Ginis for every metropolitan area with at least 1,000 members in both city and suburb. Then, we weight these Ginis by the immigrant group's city- and suburb-specific population size. Table 2 presents those population-weighted Ginis for each group in cities and suburbs. The Ginis in this table indicate the extent to which suburban immigrants tend to be on equal residential footing with whites in their area; the larger the Gini, the greater the disparity.

\section{[Table 2 about here]}

There are two major findings from Table 2. The first is that, in both suburbs and cities, white residents tend to live in lower-poverty neighborhoods than immigrants. Half of the groups have Ginis above .40 in both cities and suburbs, and the Dominican, Guatemalan, and Honduran indices exceed .60 in the cities. There are exceptions, as Chinese and Korean suburbanites are essentially at residential parity with suburban whites and Asian Indian immigrants tend to live in neighborhoods with slightly lower poverty rates than whites in both cities and suburbs. Using the Figure 2 Chinese curve as a reference, this can be visualized as the mean Indian Lorenz curves arcing above the diagonal (a negative Gini, as we have set up the calculations) rather than beneath it. ${ }^{7}$ In general, the Ginis for Asian origin groups pale in comparison to the immigrantwhite differences found for Caribbean and Latin American immigrant groups. To put the magnitude of these differences in context, the Ginis for immigrant-white inequality in neighborhood poverty for Dominican (Gini $=.59$ ), Haitian (.58), Salvadoran (.54), Guatemalan (.57), Honduran (.56), and Mexican (.52) immigrant suburbanites all exceed the Gini of .43 for

\footnotetext{
${ }^{7}$ In the case of Chinese suburbanites, the Gini is negative (Lorenz curve above the diagonal) in Figure 2 but not in Table 2. In Table 2 the Gini is no longer negative because that comparison is between Chinese and white residents who live in the same metropolitan area.
} 
black-white inequality in neighborhood poverty in the average U.S. metropolitan area in 2010 (Firebaugh and Farrell 2015).

The second major finding is that most immigrants experience lower levels of relative neighborhood disadvantage in suburban areas, as indicated by the negative signs in the column for suburban Ginis minus city Ginis in Table 2. In some cases, the city/suburb differences are quite large in absolute terms. The typical Chinese, Korean, Dominican, and Honduran suburbanite experiences poverty-based neighborhood inequality that is between .10 and .20 Gini units lower than that experienced by a coethnic city dweller. This tendency is present in varying degrees across most of the immigrant groups, with two minor exceptions and one major exception. First, cities and suburbs approach parity (with a slight city advantage) when it comes to Indian-white and Jamaican-white neighborhood poverty inequality. Second, as hinted at in the nationwide curves provided in Figure 2, the Haitian-white disparity in neighborhood poverty rates is a great deal higher in suburban areas than in principal cities $\left(\mathrm{G}_{\mathrm{s}}=.58\right.$ versus $\left.\mathrm{G}_{\mathrm{c}}=.42\right)$. To put this in context, Haitian suburbanites experience nearly twice the level of neighborhood poverty inequality as Vietnamese city inhabitants, the most disadvantaged Asian group in either cities or suburbs.

How do these relative disparities play out in absolute terms? Our focus is on neighborhood inequality relative to whites, but it is worth looking briefly at the levels of neighborhood poverty experienced by immigrant groups, particularly those found in the most unequal cities and suburbs. We calculated neighborhood poverty exposure indices for each of the groups, weighting tract poverty rates by a group's tract population share of the total group population (within a city or suburb) and summing across tracts. This neighborhood poverty exposure index measures the tract poverty rate experienced by the average immigrant group 
member in a city or suburb. Across areas and groups, our neighborhood inequality Ginis are highly correlated with neighborhood poverty exposure $(r=.721 ; \mathrm{p}<.001 ; \mathrm{N}=1,076)$ and this correlation holds whether looking at cities $(\mathrm{r}=.774 ; \mathrm{p}<.001 ; \mathrm{N}=538)$ or suburbs $(\mathrm{r}=.716 ; \mathrm{p}<$ $.001 ; \mathrm{N}=538)$. In short, immigrant neighborhood inequality relative to whites is highly associated with absolute neighborhood disadvantage as well.

We illustrate this in Figure 3 by displaying the mean neighborhood poverty exposure (weighted by group population size) in cities and suburbs by neighborhood inequality quartiles. The average immigrant in the most unequal quartile of cities — cities with neighborhood inequality Ginis above .48 — resides in a neighborhood in which more than one-quarter (25.9 percent) of the population is poor. The mean suburban neighborhood poverty rate (18.6 percent) is lower in this high inequality quartile but even here it approaches the 20 percent threshold associated with some of the most consequential impacts of concentrated poverty (Galster 2002; Jargowsky 1997). Immigrant residents in the third inequality quartile — with Ginis ranging from .27 to .48 - also experience high rates of neighborhood poverty in cities (20.4 percent) and suburbs (18.1 percent). Compare this to the average neighborhood poverty rate for whites, which is 14.5 percent in cities and 9.8 percent in suburbs. Thus, the second neighborhood inequality quartile-with Ginis ranging from .03 to .27 - is where we finally find immigrants living in local poverty environments comparable to the average white resident. The first quartile is reserved for the most residentially advantaged immigrants, many of whom reside in areas characterized by "reverse inequality" (negative Ginis) relative to whites. Their neighborhood poverty rates are quite low, though there is still a discernible gap between cities (10.6 percent) and suburbs (8.7 percent). It is important to remember that these quartiles do not represent equal segments of the 
immigrant population. Nearly half (47.1 percent) of all immigrants reside in the highest inequality profile while just a fraction of that (10.9 percent) live in the lowest inequality profile.

\subsection{Multivariate Models of Immigrant Neighborhood Inequality}

Overall, the immigrant-white gap in neighborhood poverty is narrower in suburban areas, with a few exceptions. Does this association hold after controlling for other group and metropolitan characteristics? Table 3 presents the results of regression analyses of poverty-based neighborhood inequality. ${ }^{8}$ Because we omit metropolitan areas with fewer than 1,000 group members in either city or suburb, some immigrant groups contribute more cases than others (Mexicans, for example, contribute 292 cases_-146 for suburbs and 146 for central cities_-while Haitians contribute only 22 cases). We want to know whether the neighborhood disparity between immigrants and whites remains smaller in the suburbs after we control for (a) region of the country and metropolitan characteristics such as population size and level of suburbanization, (b) the overall poverty rate and the segregation of poverty in the city/suburb, (c) the group's residential segregation from the white population, and (d) group-specific characteristics including the group's population size, poverty ratio (compared to whites), year of arrival, and English language proficiency.

The first model in Table 3 includes only the suburban dummy variable along with the metropolitan and regional controls (not shown). After taking metropolitan context into account, suburbs are characterized by .09 Gini units less immigrant neighborhood inequality than are cities. Model 2 introduces dummies for specific nativity groups, with Indian immigrants serving

\footnotetext{
${ }^{8}$ These models are unweighted though we do control for group and metro population size. Histograms indicate that the Ginis for poverty neighborhood inequality approximate normal distributions and additional analyses find that they have modest skewness and kurtosis scores $(\mathrm{s}=-.192, \mathrm{k}=-.797)$. We also note that most $(85 \%)$ U.S. metropolitan residents live in the metropolitan areas analyzed in Table 3, so we are analyzing a near population. We nonetheless report standard errors because high multicollinearity among predictors sometimes results in unstable results for data aggregated to the metropolitan level. Because standard errors are inflated by multicollinearity, the size of the standard errors provides information about the sensitivity of results to changes in the model.
} 
as the reference group. A glance at the $\mathrm{R}^{2}$ indicates that the model fits much better when we account for group differences in neighborhood inequality. Consistent with the descriptive analyses presented in Table 2, all of the groups experience more neighborhood inequality than do Indian immigrants. Dominicans, Salvadorans, Guatemalans, Hondurans, and Mexicans experience the largest neighborhood inequality levels relative to whites.

[Table 3 about here]

Is the suburban advantage simply a function of greater economic and ethnic residential integration in the periphery? Or is it due to differences in economic and cultural characteristics of immigrant suburbanites and city-dwellers? The final model in Table 3 includes controls for the overall poverty rate of the area as well as a Gini reflecting its level of poor-nonpoor residential segregation. It also includes Ginis reflecting each immigrant group's segregation from U.S.-born whites (labeled "segregation" in Table 3) and its localized population size, group poverty ratio relative to whites, percentage of recent arrivals, and English language proficiency. Introducing these variables into the model reduces the equalizing effect of suburban residence but it remains negative and statistically significant. This indicates that the city/suburb difference is not simply a function of city/suburb poverty differentials, nor is it due to suburban immigrants' smaller residential footprint, advantaged economic standing, longer duration of residence in the United States, and facility with the English language relative to their urban counterparts. That is not to say these characteristics are insignificant. As the spatial assimilation perspective predicts, areas with large enclaves of poor, recently arrived immigrants struggling with the English language are characterized by higher neighborhood inequality relative to whites. Furthermore, areas with high levels of poverty segregation in general tend to exhibit greater immigrant neighborhood inequality. Consistent with place stratification, immigrant residential segregation 
from whites has an even larger impact, with a coefficient $(B=.622)$ eclipsing that for poverty segregation $(\mathrm{B}=.375) .{ }^{9}$ However, neither of these segregation measures fully account for city/suburb differences in immigrant-white neighborhood inequality. This bolsters the case that many suburban immigrants experience fewer residential disparities than do their urban counterparts.

Inclusion of the additional controls accounts for the differences between Chinese and Indians and between Koreans and Indians, but the remainder of the nativity group coefficients remain positive and statistically significant. Aside from Cubans and Colombians, all of the nonAsian groups experience neighborhood inequality that is at least .30 Gini units higher than the Indian reference group. These persistent group differences - in most cases far exceeding the effect of suburban location—are consistent with the differentiated residential trajectories predicted by segmented assimilation. The metro effects in this full model (not shown) indicate that smaller, immigrant-rich metropolitan areas are characterized by higher levels of immigrant neighborhood inequality, all things being equal. Aside from population size $(\mathrm{B}=-.056$; $\mathrm{se}=$ $.011 ; \mathrm{p}<.001)$ and percent foreign-born $(\mathrm{B}=.412 ; \mathrm{se}=.123 ; \mathrm{p}<.01)$, none of the other metropolitan or regional controls emerge as significant predictors in Model 3.

\subsection{Group-Specific Models}

The final set of models investigates whether the suburban effect is consistent across country of origin groups. Given the limited number of cases we are unable to carry out separate multivariate analyses for every group. Instead, we run reduced models for the eight groups with at least 50 cases: Chinese, Indians, Koreans, Filipinos, Vietnamese, Salvadorans, Guatemalans,

\footnotetext{
${ }^{9} \mathrm{We}$ ran these models separately for cities and suburbs and poverty segregation was significantly associated with immigrant neighborhood inequality in cities $(\mathrm{B}=.521 ;=.166 ; \mathrm{p}<.01)$ but not in suburbs $(\mathrm{B}=.179 ; \mathrm{se}=.206 ; \mathrm{p}=$ .386). By contrast, immigrant-white residential segregation was associated with greater neighborhood inequality in both cities $(\mathrm{B}=.740 ; \mathrm{se}=.095 ; \mathrm{p}<.001)$ and suburbs $(\mathrm{B}=.723 ; \mathrm{se}=.121 ; \mathrm{p}<.001)$.
} 
and Mexicans. Table 4 includes two models for each group, the first of which includes only the suburban dummy variable and the second of which introduces the poor-nonpoor and group-white segregation Ginis along with the other group-specific characteristics. Without controls, the suburban coefficient is negative and statistically significant for six of the eight groups, though the magnitude of the difference depends on the group in question. Inclusion of controls reduces the suburban coefficient to insignificance for Asian Indians and Vietnamese. Consistent with spatial assimilation, this suggests that the observed suburban advantages are due to the fact that immigrant suburbanites in these three groups tend to be better off or more acculturated than their city counterparts, thus reducing residential disparities relative to whites. However, significant city/suburb differences remain for Chinese, Koreans, Filipinos, and Mexicans even after controlling for group characteristics.

[Table 4 about here]

Putting aside the question of suburban advantage in neighborhood inequality for immigrants, many of the results presented in Table 4 are consistent with accounts of the spatial assimilation of immigrants. Higher poverty rates relative to whites are associated with neighborhood inequality for six of the groups and English language proficiency significantly diminishes inequality for four of the groups. By contrast, year of entry has less of an impact overall and has conflicting effects for two groups. Locations in which large proportions of Chinese immigrants are recent arrivals are characterized by greater Chinese-white neighborhood inequality while the opposite is true for Mexicans.

The segregation coefficients are worthy of special attention given that segregation is so often used as a proxy for neighborhood inequality. A variety of group-specific patterns emerge when looking at residential segregation from whites. Even after controlling for group-specific 
poverty ratios, segregation magnifies neighborhood inequality for Vietnamese, Salvadorans, Guatemalans, and Mexicans. This falls in line with the place stratification perspective, which points to racialized housing markets that continue to funnel minority residents into the most disadvantaged areas. Segregation does not have the same effect in all cases, as it appears to have little impact on inequality for three of the five Asian-origin groups. The Indian model stands out because the segregation coefficient is both negative and statistically significant. In other words, the relative neighborhood poverty rates of Indian immigrants improve when they are more segregated from native whites. This is an important finding, though it is worth noting that Asian Indians do not tend to be highly segregated compared to other immigrant groups (Hall 2013; Iceland 2009).

\section{Conclusion}

With few exceptions, immigrant and white suburbanites live in more comparable localized poverty environments than do their city counterparts. Although other studies have hinted at narrower immigrant-white neighborhood differences in suburban areas, this study is, to our knowledge, the first to do so for a large sample of U.S. metropolitan areas across such a wide array of country-of-origin groups. In fact, we identify a few groups-Asian Indians, Chinese, and Koreans - that have achieved residential parity (or better) with whites in the metropolitan periphery. Overall, our findings are consistent with the view that immigrant residential attainment is occurring on more equal terms in the suburbs. The overall suburban effect remains after accounting for metropolitan context, poverty segregation, group-white segregation and poverty ratios, and group-specific acculturation characteristics.

However, this is not to say that the suburbs have become bastions of residential equality. Though immigrant suburbanites tend to reside in less unequal residential circumstances, it does 
not necessarily follow that these circumstances are as equal as they could (or should) be. By all indications, the average Caribbean or Latin American suburbanite lives in a very disparate neighborhood environment relative to the average suburban white. Among Caribbean immigrants, suburban Dominicans and Haitians are in worse shape, residentially speaking, than the city-dwellers of most other immigrant groups. Similarly, Salvadorans, Guatemalans, and Mexicans experience high levels of neighborhood inequality that are at best marginally improved in the suburbs. This latter point echoes previous research which cautions against interpreting Hispanic suburbanization as a de facto indicator of spatial assimilation (Friedman et al. 2014; Lichter et al. 2010). Moreover, many Latin American immigrants reside in overcrowded housing (Scott 2014; Hall and Greenman 2013), so a tract-based focus like ours may miss important forms of suburban residential inequality occurring at the household level. Furthermore, there are large disparities between national origin groups that remain unexplained by differences in suburbanization, poverty and acculturation. Consistent with the segmented version of spatial assimilation, the benefits of suburban residence may "cost" more for certain groups than they do for others (Alba and Logan 1991).

One limitation of our study is that our definition of suburb is admittedly broad, encompassing the entire metropolitan territory located outside principal cities. We find that the landscape of inequality is often quite different beyond city limits but these are not the only jurisdictional boundaries that matter. In many metropolitan areas the suburban ring is comprised of a hodge-podge of dozens or even hundreds of suburban municipalities, large and small. These municipalities are loci of decision-making about land use and services that bear on the settlement patterns of immigrants and the poor. As such, residential disparities may vary a great deal across municipalities within the suburban ring and there are indications that this sort of place 
stratification often occurs by design rather than happenstance (Rothwell and Massey 2009). Indeed, there is evidence that the geography of race, immigration and poverty is increasingly organized around jurisdictional domains (Farrell 2008; Fischer et al. 2004; Lichter et al. 2010, 2012). In the future, our methodological approach could be refined to enhance our understanding of place as well as neighborhood inequalities.

Finally, though we do not focus on immigrant segregation per se, the findings related to segregation are telling. Immigrant segregation in both cities and suburbs is generally associated with higher levels of neighborhood inequality. This is consistent with the place stratification perspective and with the assumptions underlying much of segregation research. However, group and city/suburb differences in neighborhood inequality persist after taking segregation into account. Furthermore, group-specific models show that while segregation is indeed associated with greater neighborhood inequality for Vietnamese and Latin American immigrants it has little impact on the inequality experienced by Chinese, Koreans, and Filipinos and appears to enhance the residential fortunes of Asian Indians. This underscores the problem with relying on residential segregation alone as a proxy for neighborhood inequality. There is clearly more to the story. Because relative residential disadvantage matters, we need to measure it directly. 


\section{Acknowledgements}

This research is supported by a grant from the National Science Foundation (BCS-1260362). 


\section{References}

Adelman, Robert M., Hui-shien Tsao, Stewart E. Tolnay, and Kyle D. Crowder. 2001. "Neighborhood Disadvantage among Racial and Ethnic Groups: Residential Location in 1970 and 1980." The Sociological Quarterly 42:603-632.

Alba, Richard, Glenn Deane, Nancy Denton, Ilir Disha, Brian McKenzie, and Jeffrey Napierala. 2014. "The Role of Immigrant Enclaves for Latino Residential Inequalities." Journal of Ethnic and Migration Studies 40:1-20.

Alba, Richard D. and John R. Logan. 1991. "Variations on Two Themes: Racial and Ethnic Patterns in the Attainment of Suburban Residence." Demography 28:431-453.

Alba, Richard D., John R. Logan, Brian J. Stults, Gilbert Marzan, and Wenquan Zhang. 1999. "Immigrant Groups in the Suburbs: A Reexamination of Suburbanization and Spatial Assimilation." American Sociological Review 64:446-460.

Allard, Scott W. and Benjamin Roth. 2010. "Strained Suburbs: The Social Service Challenges of Rising Suburban Poverty." Metropolitan Opportunity Series. Washington, DC: The Brookings Institution. Retrieved November 26, 2014 (http://www.brookings.edu/ /media/research/files/reports/2010/10/07-suburban-povertyallard-roth/1007_suburban_poverty_allard_roth.pdf).

Allison, Paul. 1978. "Measures of Inequality." American Sociological Review 43:865-880.

Argeros, Grigoris. 2013. "Suburban Residence of Black Caribbean and Black African Immigrants: A Test of the Spatial Assimilation Model." City \& Community 12:361-379.

Bischoff, Kendra and Reardon, Sean F. 2014. "Residential Segregation by Income, 1970-2009." Pp. 208-233 in Diversity and Disparities: America Enters a New Century, edited by J. R. Logan. New York: Russell Sage Foundation.

Charles, Camille Zubrinsky. 2003. "The Dynamics of Racial Residential Segregation." Annual Review of Sociology 29:167-207.

Cort, David A. 2011. "Reexamining the ethnic hierarchy of locational attainment: Evidence from Los Angeles." Social Science Research 40:1521-1533.

Crowder, Kyle, Matthew Hall, and Stewart E. Tolnay. 2011. "Neighborhood Immigration and Native Out-Migration." American Sociological Review 76:25-47.

Crowder, Kyle and Scott J. South. 2005. "Race, Class, and Changing Patterns of Migration between Poor and Nonpoor Neighborhoods." American Journal of Sociology 110:17151763.

Crowder, Kyle and Scott J. South. 2011. "Spatial and temporal dimensions of neighborhood 
effects on high school graduation." Social Science Research 40:87-106.

Cutler, David M., Edward L. Glaeser, and Jacob L. Vigdor. 2008. "Is the Melting Pot Still Hot? Explaining the Resurgence of Immigrant Segregation." Review of Economics \& Statistics 90:478-497.

Duncan, Otis D. and Beverly Duncan. 1955. "A Methodological Analysis of Segregation Indexes." American Sociological Review 20:210-217.

Dwyer, Rachel E. 2010. "Poverty, Prosperity, and Place: The Shape of Class Segregation in the Age of Extremes." Social Problems 57:114-137.

Farrell, Chad R. 2008. "Bifurcation, Fragmentation, or Integration? The Racial and Geographic Structure of Metropolitan Segregation, 1990-2000." Urban Studies 45:467-499.

Farrell, Chad R. 2016. "Immigrant Suburbanization and the Shifting Geographic Structure of Metropolitan Segregation in the United States." Urban Studies 53(1):57-76.

Fennelly, Katherine and Myron Orfield. 2008. "Impediments to the Integration of Immigrants: A Case Study in the Twin Cities." in Twenty-First Century Gateways: Immigrant Incorporation in Suburban America, edited by A. Singer, S. W. Hardwick, and C. B. Brettell. Washington, DC: Brookings Institution Press.

Firebaugh, Glenn and Chad R. Farrell. 2015. "Still Large, But Narrowing: The Sizable Decline in Racial Neighborhood Inequality In Metropolitan America, 1980-2010.” Demography (DOI 10.1007/s13524-015-0447-5).

Firebaugh, Glenn and Chad R. Farrell. 2011. "Racial Inequality in America: Neighborhood vs. Households." At the Annual Meeting of the Population Association of America, Washington D.C. (March 31).

Firebaugh, Glenn and Matthew B. Schroeder. 2009. "Does Your Neighbor's Income Affect Your Happiness?" American Journal of Sociology 115:805-831.

Fischer, Claude S., Gretchen Stockmayer, Jon Stiles, and Michael Hout. 2004. "Distinguishing the Geographic Levels and Social Dimensions of U.S. Metropolitan Segregation, 19602000." Demography 41:37-59.

Frey, William H., Jill H. Wilson, Alan Berube, and Audrey Singer. 2004. "Tracking Metropolitan America into the 21st Century: A Field Guide to the New Metropolitan and Micropolitan Definitions." in The Living Cities Census Series. Washington DC: The Brookings Institution.

Frey, William H. 2011. "Melting Pot Cities and Suburbs: Racial and Ethnic Change in Metro 
America in the 2000s." State of Metropolitan America Series. Washington, DC: The Brookings Institution. Retrieved August 19, 2014 (http://www.brookings.edu/research/papers/2011/05/04-census-ethnicity-frey).

Friedman, Samantha, Joseph Gibbons, and Chris Galvan. 2014. "Declining Segregation Through the Lens of Neighborhood Quality: Does Middle-Class and Affluent Status Bring Equality?" Social Science Research 46:155-168.

Friedman, Samantha and Emily Rosenbaum. 2007. "Does suburban residence mean better neighborhood conditions for all households? Assessing the influence of nativity status and race/ethnicity." Social Science Research 36:1-27.

Galster, George. 2002. "An Economic Efficiency Analysis of Deconcentrating Poverty Populations." Journal of Housing Economics 11:303-329.

Galster, George C., Kurt Metzger, and Ruth Waite. 1999. "Neighborhood Opportunity Structures of Immigrant Populations, 1980 and 1990." Housing Policy Debate 10:395-442.

Gastwirth, Joseph L. 1972. "The Estimation of the Lorenz Curve and the Gini Index." The Review of Economics and Statistics 54(3):306-316.

Hall, Matthew. 2013. "Residential Integration on the New Frontier: Immigrant Segregation in Established and New Destinations." Demography 50:1873-1896.

Hall, Matthew and Emily Greenman. 2013. "Housing and neighborhood quality among undocumented Mexican and Central American immigrants." Social Science Research 42:1712-1725.

Hardwick, Susan W. 2008. "Toward a Suburban Immigrant Nation." Pp. 31-50 in Twenty-First Century Gateways: Immigrant Incorporation in Suburban America., edited by A. Singer, S. W. Hardwick, and C. B. Brettell. Washington, DC: Brookings Institution Press.

Harris, Richard and Robert Lewis. 2001. "The Geography of North American Cities and Suburbs, 1900-1950: A New Synthesis." Journal of Urban History 27:262-292.

Holliday, Amy L. and Rachel E. Dwyer. 2009. "Suburban Neighborhood Poverty in U.S. Metropolitan Areas in 2000." City \& Community 8:155-176.

Howell, Aaron J. and Jeffrey M. Timberlake. 2014. "Racial and Ethnic Trends in the Suburbanization of Poverty in U.S. Metropolitan Areas, 1980-2010." Journal of Urban Affairs 36:79-98.

Iceland, John. 2009. Where We Live Now: Immigration and Race in the United States. Berkeley, CA: University of California Press.

Iceland, John and Melissa Scopilliti. 2008. "Immigrant Residential Segregation in U.S. 
Metropolitan Areas, 1990-2000." Demography 45:79-94.

Jackson, Kenneth T. 1987. Crabgrass Frontier: The Suburbanization of the United States. New York: Oxford University Press.

James, David R. and Karl E. Taeuber. 1985. "Measures of Segregation." Pp. 1-32 in Sociological Methodology, edited by N. Tuma. San Francisco, CA: Jossey-Bass.

Jargowsky, Paul A. 1997. Poverty and Place: Ghettos, Barrios, and the American City. New York: Russell Sage Foundation.

Kim, Joongbaeck. 2010. "Neighborhood Disadvantage and Mental Health: The Role of Neighborhood Disorder and Social Relationships." Social Science Research 39:260-271.

Kneebone, Elizabeth and Alan Berube. 2013. Confronting Suburban Poverty in America. Washington, DC: Brookings Institution Press.

Kruse, Kevin M. and Thomas J. Sugrue (eds). 2006. The New Suburban History. Chicago: University of Chicago Press.

Lee, Barrett A., Glenn Firebaugh, Stephen A. Matthews, Sean F. Reardon, Chad R. Farrell, and David O'Sullivan. 2008. "Beyond the Census Tract: Patterns and Determinants of Racial Segregation at Multiple Geographic Scales." American Sociological Review 73:766-791.

Lee, Barrett A., John Iceland, and Chad R. Farrell. 2014. "Is Ethnoracial Integration of the Rise? Evidence from Metropolitan and Micropolitan America Since 1980." Pp. 415-456 in Diversity and Disparities: America Enters a New Century, edited by J. R. Logan. New York: Russell Sage Foundation.

Lee, Barrett A. and Matthew Marlay. 2007. "The Right Side of the Tracks: Affluent Neighborhoods in the Metropolitan United States." Social Science Quarterly 88:766-789.

Li, Wei. 1998. "Anatomy of a New Ethnic Settlement: The Chinese Ethnoburb in Los Angeles." Urban Studies 35:479-501.

Li, Wei. 2006. From Urban Enclave to Ethnic Suburb: New Asian Communities in Pacific Rim Countries. Honolulu, HI: University of Hawaii Press.

Lichter, Daniel T. and Kenneth M. Johnson. 2009. "Immigrant Gateways and Hispanic Migration to New Destinations." International Migration Review 43:496-518.

Lichter, Daniel T., Domenico Parisi, Michael C. Taquino, and Steven Michael Grice. 2010. "Residential Segregation in New Hispanic Destinations: Cities, Suburbs, and Rural Communities Compared." Social Science Research 39:215-230.

Lichter, Daniel T., Domenico Parisi, and Michael C. Taquino. 2012. "The Geography of Exclusion: Race, Segregation, and Concentrated Poverty." Social Problems 59:364-388. 
Liu, Cathy Yang and Gary Painter. 2011. "Immigrant Settlement and Employment Suburbanisation in the US: Is There a Spatial Mismatch?" Urban Studies 49:979-1002.

John R. Logan. 2014. "Separate and Unequal in Suburbia” Census Brief prepared for Project US2010. Retrieved November 27, 2015 (http://www.s4.brown.edu/us2010).

Logan, John R., Richard D. Alba, Tom McNulty, and Brian Fisher. 1996. "Making a place in the metropolis: Locational attainment in cities and suburbs." Demography 33:443-453.

Logan, John R., Brian J. Stults, and Reynolds Farley. 2004. "Segregation of Minorities in the Metropolis: Two Decades of Change." Demography 41:1-1-22.

Logan, John R., Wenquan Zhang, and Richard D. Alba. 2002. "Immigrant Enclaves and Ethnic Communities in New York and Los Angeles." American Sociological Review 67:299322.

Lorenz, M.O. 1905. "Methods of measuring the concentration of wealth." Publications of the American Statistical Association 9 (70): 209-219.

Ludwig, Jens, Greg J. Duncan, and Paul Hirschfield. 2001. "Urban Poverty and Juvenile Crime: Evidence from a Randomized Housing-Mobility Experiment." The Quarterly Journal of Economics 116:655-679.

Massey, Douglas S. 1985. "Ethnic Residential Segregation: A Theoretical Synthesis and Empirical Review." Sociology and Social Research 69:315-350.

Massey, Douglas S. and Nancy A. Denton. 1988. "The Dimensions of Residential Segregation." Social Forces 67:281-315.

Massey, Douglas S. and Nancy A. Denton. 1989. "Hypersegregation in U.S. Metropolitan Areas: Black and Hispanic Segregation along Five Dimensions." Demography 26:373-391.

Massey, Douglas S. and Nancy A. Denton. 1993. American Apartheid: Segregation and the Making of the Underclass. Cambridge, MA: Harvard University Press.

Massey, Douglas S. 1996. "The Age of Extremes: Concentrated Affluence and Poverty in the Twenty-First Century." Demography 33:395-412.

Odem, Mary E. 2008. "Unsettled in the Suburbs: Latino Immigration and Ethnic Diversity in Metro Atlanta." in Twenty-First Century Gateways: Immigrant Incorporation in Suburban America, edited by A. Singer, S. W. Hardwick, and C. B. Brettell. Washington, DC: Brookings Institution Press. 
Osypuk, Theresa L., Sandro Galea, Nancy McArdle, and Dolores Acevedo-Garcia. 2009. "Quantifying Separate and Unequal: Racial-Ethnic Distributions of Neighborhood Poverty in Metropolitan America." Urban Affairs Review 45:25-65.

Pager, Devah and Hana Shepherd. 2008. "The Sociology of Discrimination: Racial Discrimination in Employment, Housing, Credit, and Consumer Markets." Annual Review of Sociology 34:181-209.

Portes, Alejandro and Min Zhou. 1993. "The New Second Generation: Segmented Assimilation and Its Variants." Annals of the American Academy of Political and Social Science 530:74-96.

Quillian, Lincoln. 2012. "Segregation and Poverty Concentration: The Role of Three Segregations." American Sociological Review 77:354-379.

Reardon, Sean F. and Glenn Firebaugh. 2002. "Measures of Multigroup Segregation." Sociological Methodology 32:33-67.

Rosenbaum, Emily and Samantha Friedman. 2007. The Housing Divide: How Generations of Immigrants Fare in New York's Housing Market. New York: New York University Press.

Rothwell, Jonathan and Douglas S. Massey. 2009. "The Effect of Density Zoning on Racial Segregation in U.S. Urban Areas." Urban Affairs Review 44:779-806.

Sampson, Robert J. and Patrick Sharkey. 2008. "Neighborhood Selection and the Social Reproduction of Concentrated Racial Inequality." Demography 45:1-29.

Scott, Molly M. 2015. "Mexican and Central American immigrant communities in the boom and bust housing markets of the 2000s." Urban Geography 36:29-43.

Sharkey, Patrick. 2008. "The Intergenerational Transmission of Context." American Journal of Sociology 113:931-969.

Sharkey, Patrick and Felix Elwert. 2011. "The Legacy of Disadvantage: Multigenerational Neighborhood Effects on Cognitive Ability." American Journal of Sociology 116:19341981.

Sharpe, William and Leonard Wallock. 1994. "Bold New City or Built-up 'Burb? Redefining Contemporary Suburbia." American Quarterly 46:1-30.

Singer, Audrey. 2005. "The Rise of New Immigrant Gateways: Historical Flows, Recent Settlement Trends." Pp. 41-86 in Redefining Urban and Suburban America: Evidence from Census 2000, Vol II, edited by A. Berube, B. Katz, and R. E. Lang. Washington, DC: Brookings Institution Press. 
Singer, Audrey, Susan W. Hardwick, and Caroline B. Brettell. 2008. Twenty-First Century Gateways: Immigrant Incorporation in Suburban America. Washington, DC: Brookings Institution Press.

Social Explorer. 2014. "Demographic Reports." Retrieved August 1, 2014 (www.socialexplorer.com).

South, Scott J., Kyle Crowder, and Erick Chavez. 2005. "Migration and Spatial Assimilation among U.S. Latinos: Classical versus Segmented Trajectories." Demography 42:497-521.

Timberlake, Jeffrey. 2002. "Separate, but How Unequal? Ethnic Residential Stratification, 1980 to 1990." City \& Community 1:251-266.

Timberlake, Jeffrey M. and John Iceland. 2007. "Change in Racial and Ethnic Residential Inequality in American Cities, 1970-2000." City \& Community 6:335-365.

White, Michael J. and Sharon Sassler. 2000. "Judging Not Only by Color: Ethnicity, Nativity, and Neighborhood Attainment." Social Science Quarterly 81:997-1013.

Wilson, Jill H. and Audrey Singer. 2010. "Immigrants in 2010 Metropolitan America: A Decade of Change." State of Metropolitan America Series. Washington, D.C.: The Brookings Institute. Retrieved August 19, 2014 (http://www.brookings.edu/research/papers/2011/10/13-immigration-wilson-singer).

Woldoff, Rachael A. and Seth Ovadia. 2009. "Not Getting Their Money's Worth: AfricanAmerican Disadvantages in Converting Income, Wealth, and Education into Residential Quality." Urban Affairs Review 45:66-91. 
Figure 1. Poverty-based Immigrant Neighborhood Inequality across all Metropolitan Tracts by City/Suburb Location, 2008-2012

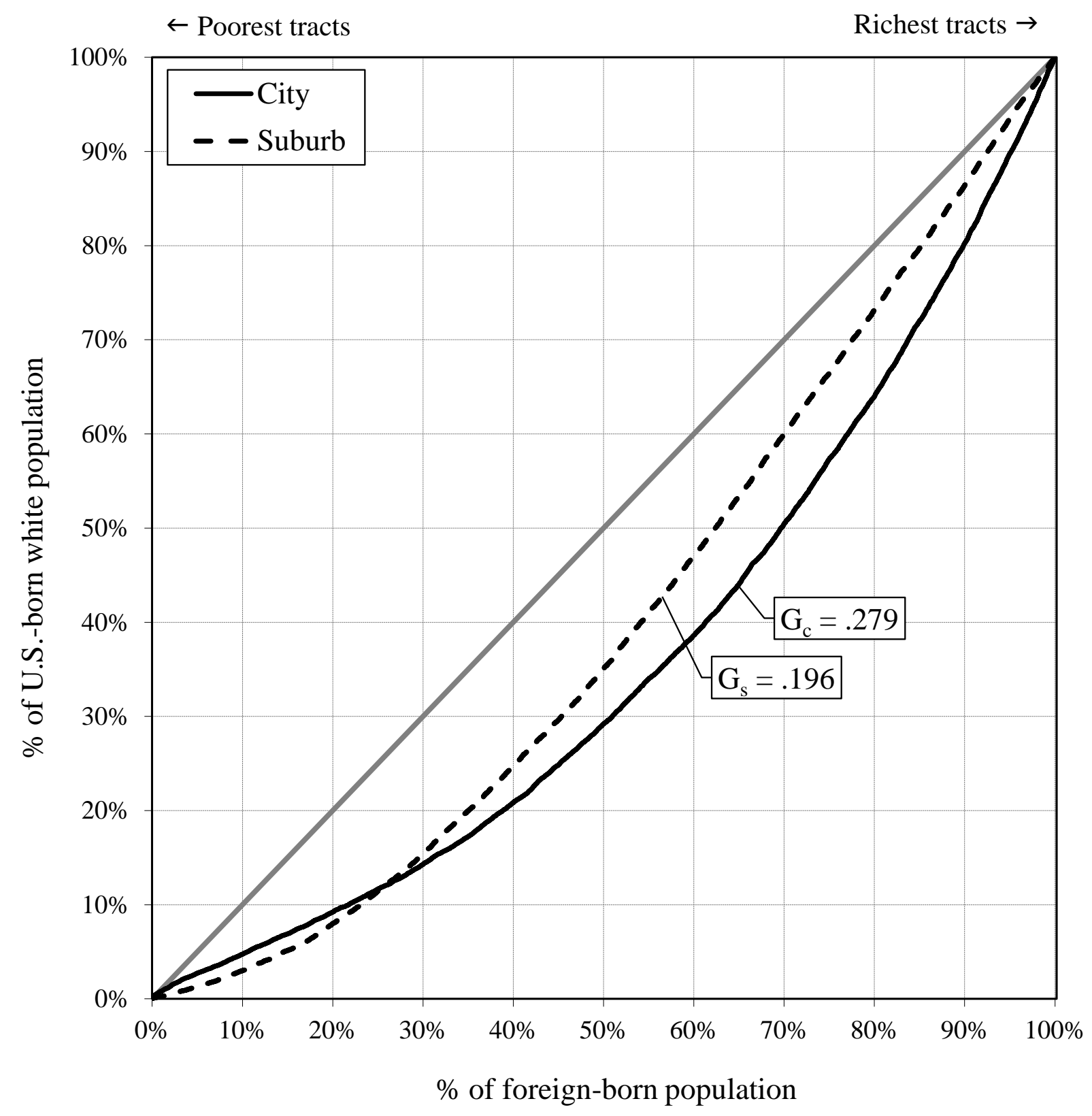


Figure 2. Poverty-based Immigrant Neighborhood Inequality across all Metropolitan Tracts, by City/Suburb Location and Selected Countries of Origin, 2008-2012
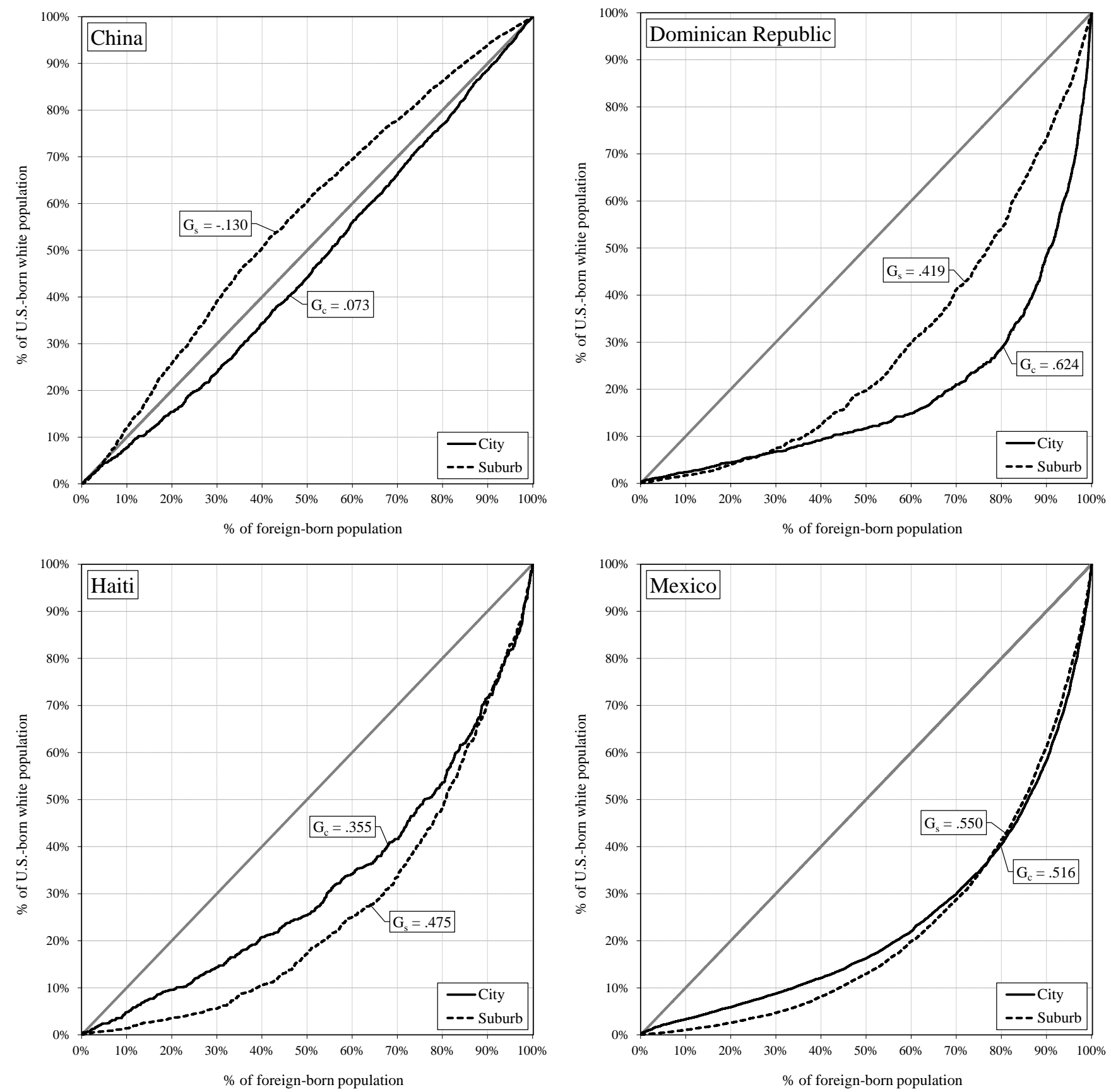
Figure 3. Immigrant Neighborhood Poverty Exposure in Cities and Suburbs, by Neighborhood Inequality Quartiles

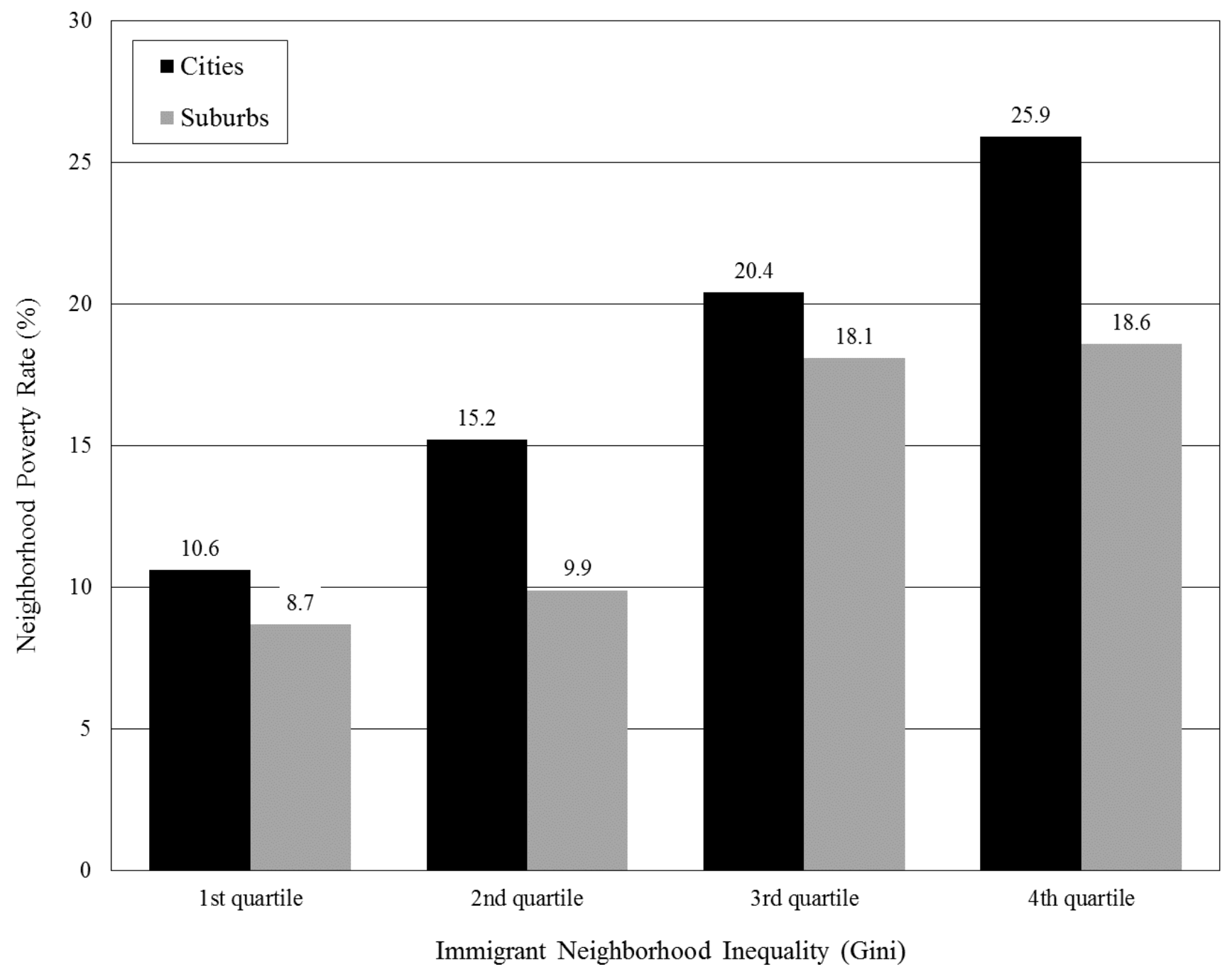


Table 1. Suburbanization of Metropolitan Immigrants by Country of Origin, 2008-2012 ${ }^{1}$

\begin{tabular}{|c|c|c|c|}
\hline & $\begin{array}{c}\text { Suburban } \\
\text { population }\end{array}$ & $\begin{array}{c}\% \\
\text { suburban } \\
\end{array}$ & $\begin{array}{c}\% \text { of suburban } \\
\text { foreign-born }\end{array}$ \\
\hline U.S.-born & $159,738,255$ & 63.4 & - \\
\hline White & $105,858,074$ & 72.6 & - \\
\hline $\begin{array}{l}\text { Foreign-born } \\
\text { Asia }\end{array}$ & $19,327,974$ & 52.1 & 100.0 \\
\hline China & 890,480 & 43.7 & 4.6 \\
\hline India & $1,054,479$ & 60.0 & 5.5 \\
\hline Korea & 557,416 & 55.1 & 2.9 \\
\hline Philippines & 903,235 & 53.3 & 4.7 \\
\hline Vietnam & 599,262 & 50.5 & 3.1 \\
\hline \multicolumn{4}{|l|}{ Caribbean } \\
\hline Cuba & 729,271 & 71.6 & 3.8 \\
\hline Dom. Rep. & 331,202 & 39.3 & 1.7 \\
\hline Haiti & 335,092 & 60.2 & 1.7 \\
\hline Jamaica & 348,399 & 53.8 & 1.8 \\
\hline \multicolumn{4}{|l|}{$\underline{\text { Latin America }}$} \\
\hline Colombia & 410,538 & 65.9 & 2.1 \\
\hline El Salvador & 605,426 & 52.4 & 3.1 \\
\hline Guatemala & 361,602 & 47.6 & 1.9 \\
\hline Honduras & 229,337 & 49.3 & 1.2 \\
\hline Mexico & $4,993,615$ & 47.7 & 25.8 \\
\hline
\end{tabular}

1. Estimates are based on total metropolitan population after excluding tracts with large group-quarters populations. 
Table 2. Poverty-Based Neighborhood Inequality in Cities and Suburbs by Country of Origin, 2008-2012 ${ }^{\mathrm{a}}$

\begin{tabular}{|c|c|c|c|}
\hline & City & Suburb & Diff. \\
\hline \multicolumn{4}{|l|}{ Asia } \\
\hline China ( $\mathrm{N}=58$ metros $)$ & $\begin{array}{c}.207 \\
(.177)\end{array}$ & $\begin{array}{c}.007 \\
(.175)\end{array}$ & -.200 \\
\hline India $(\mathrm{N}=51)$ & $\begin{array}{l}-.020 \\
(.138)\end{array}$ & $\begin{array}{l}-.015 \\
(.143)\end{array}$ & .005 \\
\hline Korea $(\mathrm{N}=31)$ & $\begin{array}{c}.131 \\
(.137)\end{array}$ & $\begin{array}{c}.011 \\
(.141)\end{array}$ & -.120 \\
\hline Philippines $(\mathrm{N}=48)$ & $\begin{array}{c}.173 \\
(.107)\end{array}$ & $\begin{array}{c}.101 \\
(.143)\end{array}$ & -.072 \\
\hline Vietnam $(\mathrm{N}=38)$ & $\begin{array}{c}.289 \\
(.121)\end{array}$ & $\begin{array}{c}.274 \\
(.226)\end{array}$ & -.015 \\
\hline \multicolumn{4}{|l|}{ Caribbean } \\
\hline Cuba $(\mathrm{N}=19)$ & $\begin{array}{c}.471 \\
(.161)\end{array}$ & $\begin{array}{c}.406 \\
(.084)\end{array}$ & -.065 \\
\hline Dom. Rep. $(\mathrm{N}=13)$ & $\begin{array}{c}.688 \\
(.064)\end{array}$ & $\begin{array}{c}.592 \\
(.181)\end{array}$ & -.096 \\
\hline Haiti $(\mathrm{N}=11)$ & $\begin{array}{c}.419 \\
(.171)\end{array}$ & $\begin{array}{c}.583 \\
(.059)\end{array}$ & .164 \\
\hline Jamaica $(\mathrm{N}=17)$ & $\begin{array}{c}.341 \\
(.099)\end{array}$ & $\begin{array}{c}.358 \\
(.114)\end{array}$ & .017 \\
\hline \multicolumn{4}{|l|}{ Latin America } \\
\hline Colombia $(\mathrm{N}=24)$ & $\begin{array}{c}.266 \\
(.092)\end{array}$ & $\begin{array}{c}.243 \\
(.176)\end{array}$ & -.023 \\
\hline El Salvador $(\mathrm{N}=34)$ & $\begin{array}{c}.598 \\
(.105)\end{array}$ & $\begin{array}{c}.543 \\
(.123)\end{array}$ & -.055 \\
\hline Guatemala $(\mathrm{N}=30)$ & $\begin{array}{c}.626 \\
(.144)\end{array}$ & $\begin{array}{c}.567 \\
(.138)\end{array}$ & -.059 \\
\hline Honduras $(\mathrm{N}=17)$ & $\begin{array}{c}.684 \\
(.122)\end{array}$ & $\begin{array}{c}.559 \\
(.104)\end{array}$ & -.125 \\
\hline $\operatorname{Mexico}(\mathrm{N}=147)$ & $\begin{array}{c}.575 \\
(.117) \\
\end{array}$ & $\begin{array}{c}.521 \\
(.131)\end{array}$ & -.054 \\
\hline
\end{tabular}

a. Includes only metropolitan areas with at least 1,000 group members in both cities and suburbs. Ginis are weighted by group-specific population sizes (standard deviations appear in parentheses). Negative Ginis indicate that the immigrant group is residentially advantaged relative to U.S.-born whites. 
Table 3. City/Suburb and Country-of-Origin Differences in Immigrant Neighborhood Inequality, Before and After Controlling for Group and Location Characteristics ${ }^{\mathrm{a}}$

\begin{tabular}{|c|c|c|c|c|c|c|}
\hline & \multicolumn{2}{|c|}{ Model 1} & \multicolumn{2}{|c|}{ Model 2} & \multicolumn{2}{|c|}{ Model 3} \\
\hline & Coef. & SE & Coef. & $\mathrm{SE}$ & Coef. & SE \\
\hline \multicolumn{7}{|l|}{ Location characteristics } \\
\hline Suburb & $-.085 * * *$ & $(.014)$ & $-.085 * * *$ & $(.015)$ & $-.070 * * *$ & $(.015)$ \\
\hline \multicolumn{7}{|l|}{ City (omitted) } \\
\hline Poverty rate & & & & & .289 & $(.157)$ \\
\hline Poverty seg. (Gini) & & & & & $.375^{* *}$ & $(.123)$ \\
\hline \multicolumn{7}{|l|}{ Group characteristics } \\
\hline Segregation (Gini) & & & & & $.622 * * *$ & $(.081)$ \\
\hline Pop. size (logged) & & & & & $.046^{* * *}$ & $(.006)$ \\
\hline Poverty ratio ${ }^{\mathrm{b}}$ & & & & & $.055^{* * *}$ & $(.006)$ \\
\hline Recent arrivals ${ }^{\mathrm{b}}$ & & & & & .066 & $(.051)$ \\
\hline English proficiency ${ }^{\mathrm{b}}$ & & & & & $-.172 * *$ & $(.054)$ \\
\hline \multicolumn{7}{|l|}{ Country of origin } \\
\hline \multicolumn{7}{|l|}{ Asia } \\
\hline China & & & $.062 * *$ & $(.019)$ & .037 & $(.021)$ \\
\hline \multicolumn{7}{|l|}{ India (omitted) } \\
\hline Korea & & & $.045^{* *}$ & $(.017)$ & -.002 & $(.025)$ \\
\hline Philippines & & & $.145^{* * *}$ & $(.019)$ & $.194 * * *$ & $(.019)$ \\
\hline Vietnam & & & $.230 * * *$ & $(.025)$ & $.160 * * *$ & $(.028)$ \\
\hline \multicolumn{7}{|l|}{ Caribbean } \\
\hline Cuba & & & $.278 * * *$ & $(.031)$ & $.266 * * *$ & $(.027)$ \\
\hline Dominican Rep. & & & $.513 * * *$ & $(.030)$ & $.386 * * *$ & $(.031)$ \\
\hline Haiti & & & $.477 * * *$ & $(.040)$ & $.371 * * *$ & $(.029)$ \\
\hline Jamaica & & & $.383 * * *$ & $(.025)$ & $.390 * * *$ & $(.032)$ \\
\hline \multicolumn{7}{|l|}{ Latin America } \\
\hline Colombia & & & $.197 * * *$ & $(.022)$ & $.187 * * *$ & $(.024)$ \\
\hline El Salvador & & & $.549 * * *$ & $(.022)$ & $.392 * * *$ & $(.028)$ \\
\hline Guatemala & & & $.548 * * *$ & $(.033)$ & $.359 * * *$ & $(.035)$ \\
\hline Honduras & & & $.613 * * *$ & $(.025)$ & $.424 * * *$ & $(.033)$ \\
\hline Mexico & & & $.566 * * *$ & $(.021)$ & $.371 * * *$ & $(.024)$ \\
\hline Intercept & $.858 * *$ & $(.242)$ & -.386 & $(.183)$ & $-.371 *$ & $(.180)$ \\
\hline $\mathrm{R}^{2}$ & .105 & & .689 & & .788 & \\
\hline $\mathrm{N}$ & 1,034 & & 1,034 & & 1,034 & \\
\hline
\end{tabular}

Note: $* \mathrm{p}<.05 ; * * \mathrm{p}<.01 ; * * * \mathrm{p}<.001 ;$ Standard errors appear in parentheses and are adjusted for clustered observations within metropolitan areas.

a. All models control for region of country and additional metropolitan characteristics (not shown). See text for details.

b. Based on 2006-10 ACS estimates. 
Table 4. Immigrants' Suburban Advantage in Neighborhood Inequality by Country of Origin, Before and After Controlling for Poverty Segregation and Group Characteristics ${ }^{\mathrm{a}}$

\begin{tabular}{|c|c|c|c|c|c|c|c|c|}
\hline Location characteristics & \multicolumn{2}{|c|}{ China } & \multicolumn{2}{|c|}{ India } & \multicolumn{2}{|c|}{ Korea } & \multicolumn{2}{|c|}{ Philippines } \\
\hline Suburb & $-.190 * * *$ & $-.119 * *$ & $-.093 * *$ & -.048 & $-.091 * *$ & $-.094 *$ & $-.074 * *$ & $-.078 * *$ \\
\hline \multicolumn{9}{|l|}{ City (omitted) } \\
\hline Poverty seg. (Gini) & & -.222 & & -.142 & & -.304 & & -.120 \\
\hline \multicolumn{9}{|l|}{$\underline{\text { Group characteristics }}$} \\
\hline Segregation (Gini) & & -.165 & & $-.697 *$ & & -.062 & & .295 \\
\hline Pop. size (logged) & & .030 & & .014 & & $.039 *$ & & $.037 * *$ \\
\hline Poverty ratio $^{a}$ & & $.077 * *$ & & $.074^{*}$ & & $.047 *$ & & .022 \\
\hline Recent arrivals $^{\mathrm{a}}$ & & $.437 * *$ & & .248 & & -.075 & & -.081 \\
\hline English proficiency $^{a}$ & & -.414 & & -.190 & & .036 & & $-1.073^{*}$ \\
\hline Intercept & $.084 * *$ & .085 & -.031 & .449 & .019 & -.237 & $.098 * * *$ & .635 \\
\hline $\mathrm{R}^{2}$ & .183 & .344 & .068 & .226 & .109 & .306 & .062 & .243 \\
\hline \multirow[t]{2}{*}{$\mathrm{N}$} & 116 & 116 & 102 & 102 & 62 & 62 & 88 & 88 \\
\hline & \multicolumn{2}{|c|}{ Vietnam } & \multicolumn{2}{|c|}{ El Salvador } & \multicolumn{2}{|c|}{ Guatemala } & \multicolumn{2}{|c|}{ Mexico } \\
\hline \multicolumn{9}{|l|}{$\underline{\text { Location characteristics }}$} \\
\hline Suburb & $-.127 * * *$ & -.057 & -.045 & -.018 & -.072 & -.066 & $-.049 *$ & $-.056 * *$ \\
\hline \multicolumn{9}{|l|}{ City (omitted) } \\
\hline Poverty seg. (Gini) & & .310 & & .153 & & .395 & & $.318^{*}$ \\
\hline \multicolumn{9}{|l|}{ Group characteristics } \\
\hline Segregation (Gini) & & $.637 *$ & & .907 & & $.727 * *$ & & $.753 * * *$ \\
\hline Pop. size (logged) & & $.060 * * *$ & & $.042 * *$ & & $.051 * *$ & & $.016 * *$ \\
\hline Poverty ratio $^{a}$ & & $.064^{*}$ & & .016 & & $.044^{*}$ & & $.045 * * *$ \\
\hline Recent arrivals $^{\mathrm{a}}$ & & -.167 & & -.025 & & -.271 & & $-.385 * * *$ \\
\hline English proficiency $^{\mathrm{a}}$ & & $-.896 * *$ & & $-.473 *$ & & -.435 & & $-.432 * * *$ \\
\hline Intercept & $.218 * * *$ & -.440 & $.497 * * *$ & -.482 & $.533 * * *$ & -.494 & $.465 * * *$ & -.015 \\
\hline $\mathrm{R}^{2}$ & .103 & .545 & .020 & .366 & .037 & .597 & .018 & .555 \\
\hline $\mathrm{N}$ & 74 & 74 & 60 & 60 & 52 & 52 & 292 & 292 \\
\hline
\end{tabular}

Note: $* \mathrm{p}<.05 ; * * \mathrm{p}<.01 ; * * * \mathrm{p}<.001$

a. Based on 2006-10 ACS estimates. 